\title{
Controlling the Structural and Physical Properties of as-Synthesized Co-Mn Ferrite Nanoparticles by Adding Cr Ions
}

\author{
E. H. El-Ghazzawy*, T. M. Meaz, M. M. Seada \\ Physics Department, Faculty of Science, Tanta University, \\ Tanta 31527, Egypt
}

In this paper, mixed spinel Co-Mn-Cr ferrite with varying chromium content have been investigated to deduce the relation between the structure and some physical properties; electric, optical and magnetic.

Nano-crystalline $\mathrm{Co}_{0.7} \mathrm{Mn}_{0.3} \mathrm{Cr}_{x} \mathrm{Fe}_{2-x} \mathrm{O}_{4}(x=0.0,0.2,0.4,0.6,0.8$, and 1) were synthesized via co-precipitation route. The obtained particle size from transmission electron microscope (TEM) micrographs is close to the crystallite size calculated from X-ray diffraction (XRD) by Sherrer's formula, and the particle size distribution is regular. The infrared spectra represent two strong absorption bands around $600-400 \mathrm{~cm}^{-1}$, which confirm the presence of $M-O$ stretching bond. The mechanical properties enhanced by adding $\mathrm{Cr}^{3+}$ ions. The optical band-gap calculated from $\mathrm{UV}$ visible spectroscopy is quite affected by adding $\mathrm{Cr}^{3+}$ ions because of particle size reduction. The saturation magnetization $\left(M_{s}\right)$ and the coercivity $\left(H_{c}\right)$ decrease with $\mathrm{Cr}^{3+}$ ions substitution. The variations of the electrical conductivity and drift mobility with temperature were also investigated. The conduction mechanism changed from electron hopping to polaron hopping by raising the temperature. Superparamagnetic $\mathrm{Co}_{0.7} \mathrm{Mn}_{0.3} \mathrm{Cr}_{x} \mathrm{Fe}_{2-x} \mathrm{O}_{4}(x \geq 0.6)$ nanocrystals can be used in biomedical applications and low power-loss applications. The sample $\mathrm{Co}_{0.7} \mathrm{Mn}_{0.3} \mathrm{Cr}_{0.2} \mathrm{Fe}_{1.8} \mathrm{O}_{4}$ has high squareness ratio $\left(M_{r} / M_{s}\right)$ and, it may be suitable for memory applications.

\section{Introduction}

The particle geometry and internal structure of magnetic nanostructure materials, such as ferrites, differs drastically from their bulk counterparts that makes these materials possess interesting physical properties and have promising applications [1]. These materials have technological applications in highfrequency devices as electromagnets, magnetic bulk cores, and microwave absorbers. On the other hand, they have biological applications as in magnetic fluids, drug delivery and as contrast agents in magnetic resonance imaging [2]. 
In this manuscript, we have investigated the properties of co-precipitated mixed spinel ferrites contain cobalt, manganese and chromium ions. Where Manganese ferrite has been used extensively in the microwave and magnetic recording applications [3]. And cobalt ferrite $\mathrm{CoFe}_{2} \mathrm{O}_{4}$ has a wide range of applications in high-frequency devices and memory cores because cobalt ferrite has a unique property over the rest of ferrites which is high magneto-crystalline anisotropy [4]. $\mathrm{CoFe}_{2} \mathrm{O}_{4}$ also has high Curie temperature $T_{c}$, reasonable saturation magnetization, and high coercivity [4]. Both $\mathrm{MnFe}_{2} \mathrm{O}_{4}$ and $\mathrm{CoFe}_{2} \mathrm{O}_{4}$ are recognized as mixed inverse spinel but the degree of inversion depends basically upon the preparation conditions including sintering temperature [5] [6].

The existence of nonmagnetic trivalent or tetravalent cations has a great influence on the physical properties of spinel ferrites particularly magnetic, elastic and electric properties [5]. These features can be controlled by replacing iron ions with other metallic ions in these materials to be convenient for various applications. For this purpose, we use chromium ions $\left(\mathrm{Cr}^{3+}\right)$, which have antiferromagnetic nature and prefer the octahedral site occupation [7], to obtain samples with different properties.

Moreover, it is important to study the elastic properties of materials to get beneficial information about the structural nature and binding characteristics between adjacent atoms [8].

M. A. Amer et al. [9] had studied the effect of $\mathrm{Cr}^{3+}$ substitution on the properties of $\mathrm{FeCr}_{x} \mathrm{Fe}_{2-\mathrm{x}} \mathrm{O}_{4}$. They found that some structural parameters increase with $\mathrm{Cr}^{3+}$ addition and others decrease.

M. Raghasudha et al. [10] had examined the magnetic properties of $\mathrm{CoCr}_{\mathrm{x}} \mathrm{Fe}_{2-\mathrm{x}} \mathrm{O}_{4}$ and confirmed the formation of magnetically soft materials which can be used in transformer and motor cores. A. Manikandan et al. [11] had investigated the influence of $\mathrm{Co}^{2+}$ substitution on the properties of $\mathrm{Co}_{x} \mathrm{Mn}_{1-\mathrm{x}} \mathrm{Fe}_{2} \mathrm{O}_{4}$. The most important conclusion they reached is that $\mathrm{Co}_{x} \mathrm{Mn}_{1-x} \mathrm{Fe}_{2} \mathrm{O}_{4}$ nano-crystals can be used as catalysts for the conversion of benzyl alcohol to benzaldehyde with a conversion efficiency of $87.32 \%$ for pure $\mathrm{MnFe}_{2} \mathrm{O}_{4}$ and $94.28 \%$ for the $\mathrm{Co}_{0.6} \mathrm{Mn}_{0.4} \mathrm{Fe}_{2} \mathrm{O}_{4}$ spinel as a catalyst [11].

In the present work, mixed $\mathrm{CoMnCr}$ ferrites have been prepared and investigated to examine the correlation between the chemical structure and the important physical properties such as optical, electric and magnetic properties.

\section{Experimental}

\subsection{Sample preparation}

A series of $\mathrm{Co}_{0.7} \mathrm{Mn}_{0.3} \mathrm{Cr}_{x} \mathrm{Fe}_{2-\mathrm{x}} \mathrm{O}_{4}$ ferrite nanoparticles $(\mathrm{x}=0.0,0.2,0.4$, $0.6,0.8$, and 1) have been prepared by co-precipitating aqueous salt solutions in alkaline medium. Solutions of $\mathrm{CoCl}_{2} \cdot 6 \mathrm{H}_{2} \mathrm{O}, \mathrm{MnCl}_{2} \cdot 4 \mathrm{H}_{2} \mathrm{O}, \mathrm{CrCl}_{3} \cdot 6 \mathrm{H}_{2} \mathrm{O}$, and $\mathrm{FeCl}_{3}$ 
in the required stoichiometric ratios have been used, and the preparation method has been published before [7]. The precipitated powders have been collected and washed by distilled water then dried at $80^{\circ} \mathrm{C}$ for $24 \mathrm{~h}$ and ground in an agate mortar to obtain ultrafine powders.

\subsection{Characterization and Measurements}

The as-prepared nanoparticles have been characterized by X-ray diffraction using $\left(\mathrm{Cu}-\mathrm{K}_{\alpha}\right.$ radiation with $\left.\lambda=1.54 \AA\right)$ and FTIR spectroscopy using Bruker Tensor 27 in the range of $200-5000 \mathrm{~cm}^{-1}$. The magnetization measurements have been carried out at room temperature up to the maximum field of $18 \mathrm{KOe}$ by using Model Lake Shore 7410. The optical absorption spectra in the visible and ultraviolet region have been recorded by using a UV/VIS spectrophotometer in the wavelength region $200-1100 \mathrm{~nm}$. The average particle size of the samples has been determined by a transmission electron microscope (TEM) (JEOL JEM2100). The direct current (DC) electrical conductivity has been measured for samples $(\mathrm{x}=0.2,0.6$, and 1$)$ by the two-probe method as a function of temperature in the range of $\mathrm{T}\left(40-400^{\circ} \mathrm{C}\right)$.

\section{Results and Discussion}

\subsection{X-ray Analysis}

Figure (1) shows the XRD patterns recorded for the as-prepared $\mathrm{Co}_{0.7} \mathrm{Mn}_{0.3} \mathrm{Cr}_{\mathrm{X}} \mathrm{Fe}_{2-\mathrm{x}} \mathrm{O}_{4}$. The diffracted signals of cubic spinel at the planes (111), (220), (311), (400), (422), (511) and (440) appear obviously in the samples ( $\mathrm{x}=0$, 0.2 ) only [12], but the signals in the other samples become broader and less obvious because of the significantly reduced average crystallite size by increasing $\mathrm{Cr}^{3+}$ ions ratio and therefore the samples seem amorphous [13]. From Table 1, it is observed that the calculated lattice constant ' $a^{\prime}\left(a=d \sqrt{h^{2}+k^{2}+l^{2}}\right)$ and average crystallite size ' $R$ ' (calculated from Scherrer's formula $R=0.9 \lambda / \beta_{1 / 2} \cos \theta$ ) decrease with $\mathrm{Cr}^{3+}$ ion substitution.

This occurs because the smaller $\mathrm{Cr}^{3+}$ ions $(0.63 \AA)$ enter the octahedral sites instead of the larger $\mathrm{Fe}^{3+}$ ions $(0.67 \AA)$ which leads to contraction of bond lengths in octahedral sites, and the reduction in the unit cell volume [14]. Consequently, the X-ray density increases and the porosity decreases. Additionally, the magnetic ions' distance (jump length) in the tetrahedral A-site $\left(L_{A}\right)$, octahedral B-site $\left(L_{B}\right)$ and shared sites $\left(L_{A-B}\right)$ have been calculated using the relations [12]:

$$
L_{A-A}=a \frac{\sqrt{3}}{4}, \quad L_{B-B}=a \frac{\sqrt{2}}{4} \quad \text { and } \quad L_{A-B}=a \frac{\sqrt{11}}{8}
$$

The jump length (hopping length) depends on the lattice constant and consequently decreases with increasing $\mathrm{Cr}^{3+}$ ions concentration (Table 1) [15]. 


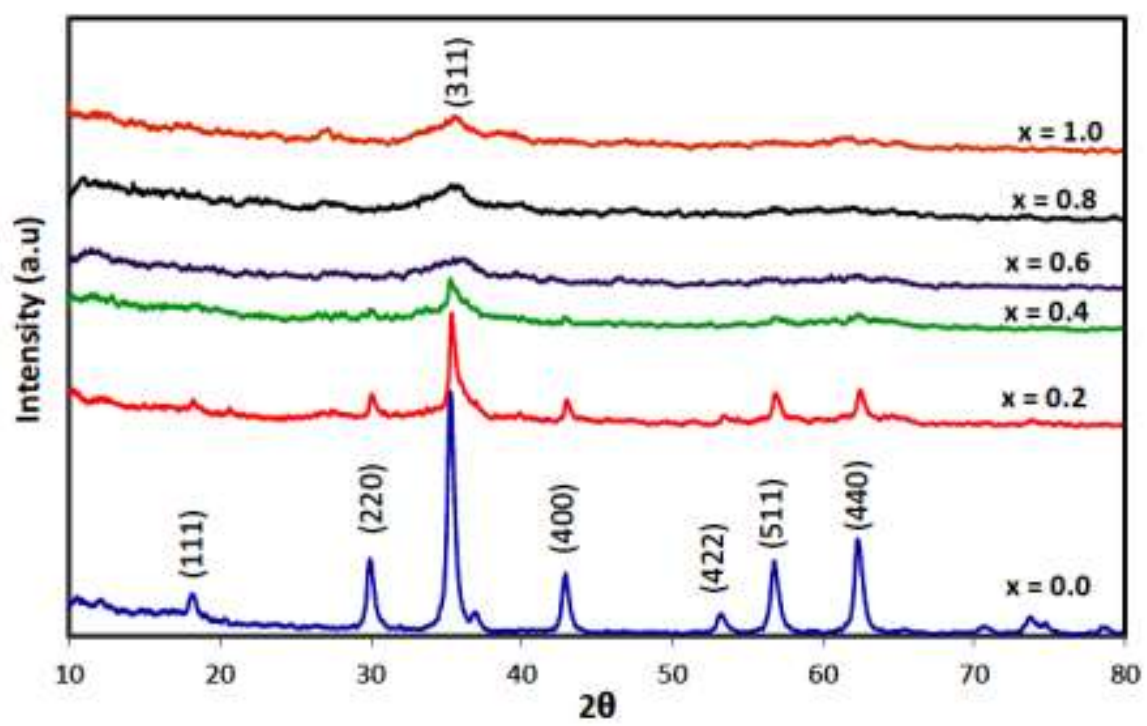

Figure (1): The $\mathrm{X}$-ray diffraction (XRD) patterns of the as-prepared $\mathrm{Co}_{0.7} \mathrm{Mn}_{0.3} \mathrm{Cr}_{\mathrm{x}} \mathrm{Fe}_{2-\mathrm{x}} \mathrm{O}_{4}$ samples.

Table (1): The Lattice constant, Average crystallite size $R$ from XRD (nm), Average particle size $D$ from TEM $(\mathrm{nm})$, X-ray density $\rho_{x}\left(\mathrm{~g} / \mathrm{cm}^{3}\right)$, Porosity P (\%), $L_{A-A}(\AA), L_{B-B}(\AA)$ and $L_{A-B}(\AA)$ of the as-prepared $\left(\mathrm{Co}_{0.7} \mathrm{Mn}_{0.3} \mathrm{Cr}_{\mathrm{x}} \mathrm{Fe}_{2-\mathrm{x}} \mathrm{O}_{4}\right)$ samples.

\begin{tabular}{|c|c|c|c|c|c|c|c|c|}
\hline $\mathrm{X}$ & $\begin{array}{c}\text { Lattice } \\
\text { constant }(a) \\
(\AA)\end{array}$ & $\begin{array}{c}R \\
\text { from XRD } \\
(\mathrm{nm})\end{array}$ & $\begin{array}{c}D \\
\text { from TEM } \\
(\mathrm{nm})\end{array}$ & $\begin{array}{c}\rho_{x} \\
\left(\mathrm{~g} / \mathrm{cm}^{3}\right)\end{array}$ & $\begin{array}{c}\mathrm{P} \\
(\%)\end{array}$ & $\begin{array}{c}L_{A-A} \\
(\AA)\end{array}$ & $\begin{array}{c}L_{B-B} \\
(\AA)\end{array}$ & $\begin{array}{c}L_{A-B} \\
(\AA)\end{array}$ \\
\hline 0 & 8.431 & 21.1 & 25 & 5.174 & 51.4 & 3.651 & 2.981 & 3.495 \\
\hline 0.2 & 8.399 & 18.4 & 3.5 & 5.216 & 51.7 & 3.637 & 2.969 & 3.482 \\
\hline 0.4 & 8.391 & 5.3 & 3 & 5.214 & 51.0 & 3.633 & 2.967 & 3.479 \\
\hline 0.6 & 8.380 & 3.8 & ----- & 5.217 & 50.2 & 3.629 & 2.963 & 3.474 \\
\hline 0.8 & 8.368 & 3.7 & ----- & 5.222 & 49.7 & 3.623 & 2.959 & 3.469 \\
\hline 1 & 8.358 & 2.4 & 2.5 & 5.223 & 49.2 & 3.619 & 2.955 & 3.465 \\
\hline
\end{tabular}

\subsection{Infrared Spectra:}

IR spectrum of a chemical substance is its recognition code. Four absorption bands only known to appear in ferrites; $v_{1}, v_{2}, v_{3}$ and $v_{A}$ have been observed in the spectra of $\mathrm{Co}_{0.7} \mathrm{Mn}_{0.3} \mathrm{Cr}_{\mathrm{x}} \mathrm{Fe}_{2-\mathrm{x}} \mathrm{O}_{4}$ samples, as shown in Figure 2 and listed in Table 2. $v_{1}\left(585\right.$ to $\left.595 \mathrm{~cm}^{-1}\right)$ and $v_{2}\left(400\right.$ to $\left.509 \mathrm{~cm}^{-1}\right)$, are ascribed to the stretching vibrations of $\mathrm{Fe}^{3+}-\mathrm{O}^{2-}$ bonds at $\mathrm{A}$-sites and intrinsic vibrations of $\mathrm{Fe}^{3+}-\mathrm{O}^{2-}$ and $\mathrm{Cr}^{3+}-\mathrm{O}^{2-}$ bonds at $\mathrm{B}$-sites, respectively [16] [17]. $v_{1}$ is nearly 
constant, but $v_{2}$ has a slight shift to higher frequencies by adding $\mathrm{Cr}^{3+}$ ions. This shift may be due to the variation in cation-oxygen bond length resulting from replacing $\mathrm{Fe}^{3+}$ ions by smaller $\mathrm{Cr}^{3+}$ ions at the octahedral sites [9]. The cation distribution over $\mathrm{A}$ and $\mathrm{B}$ sites influences the width of the spectral bands that increases with $\mathrm{Cr}^{3+}$ ions addition [15]. It is obvious that $v_{1}>v_{2}$ because the tetrahedral site bonds are shorter than those of the octahedral ones [18]. The weak band $v_{3}$ in the range of 320 to $325 \mathrm{~cm}^{-1}$ results from the existence of divalent metal ions $\left(\mathrm{Fe}^{2+}\right.$ or $\left.\mathrm{Co}^{2+}\right)$ in the B-sites [19]. The triple band around $1600 \mathrm{~cm}^{-1}$ is related to the hydroxyl groups $\mathrm{H}-\mathrm{O}-\mathrm{H}$ bending vibrations [12]. The weak absorption band $v_{A}$ is usually ascribed as due to the presence of divalent ions in the A-sites [12].

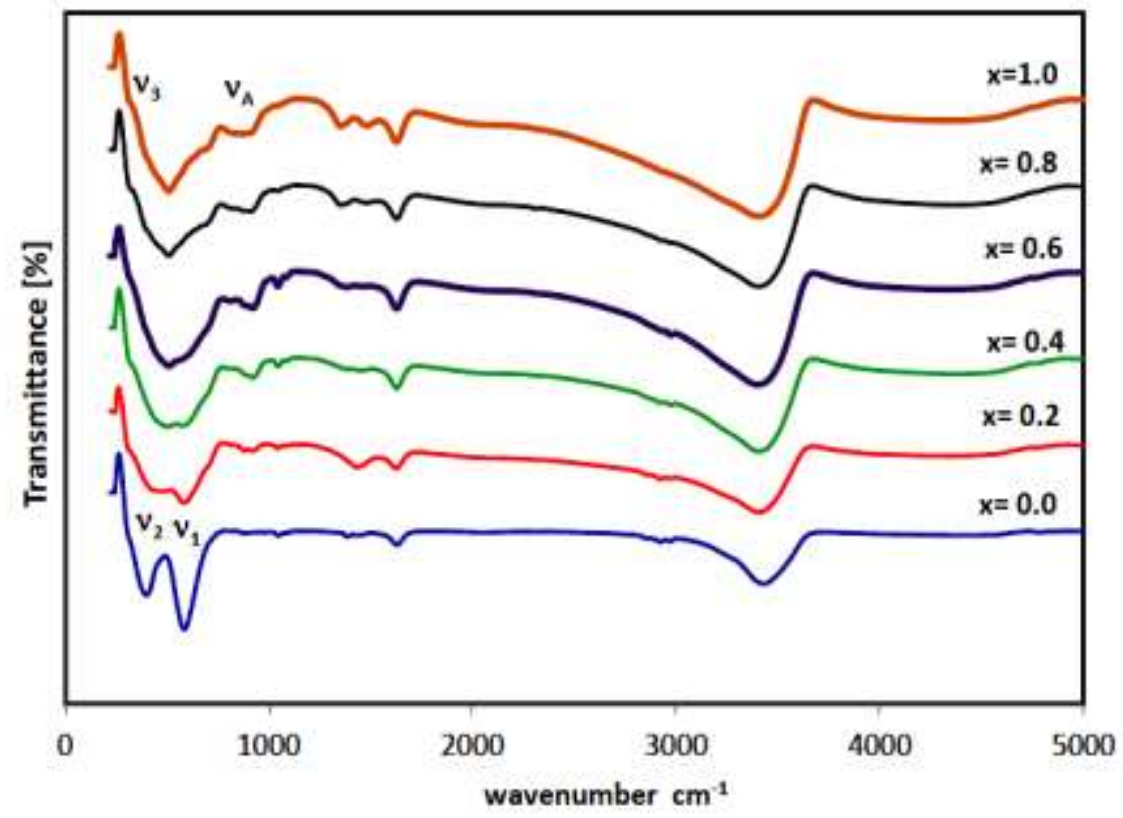

Figure (2): IR spectra of the as-prepared $\mathrm{Co} 0.7 \mathrm{Mn} 0.3 \mathrm{CrxFe} 2-\mathrm{xO} 4$ samples.

Table (2): Values of IR absorption bands of the as-prepared $\left(\mathrm{Co}_{0.7} \mathrm{Mn}_{0.3} \mathrm{Cr}_{\mathrm{x}} \mathrm{Fe}_{2-\mathrm{x}} \mathrm{O}_{4}\right)$ samples.

\begin{tabular}{|c|c|c|c|c|}
\hline $\mathbf{X}$ & $\begin{array}{c}\mathbf{v}_{\mathbf{1}} \\
\left(\mathbf{c m}^{-\mathbf{1}}\right)\end{array}$ & $\begin{array}{c}\mathbf{v}_{\mathbf{2}} \\
\left(\mathbf{c m}^{\mathbf{- 1}}\right)\end{array}$ & $\begin{array}{c}\mathbf{v}_{\mathbf{3}} \\
\left(\mathbf{c m}^{\mathbf{- 1}}\right)\end{array}$ & $\begin{array}{c}\mathbf{v}_{\mathbf{A}} \\
\left(\mathbf{c m}^{\mathbf{- 1}}\right)\end{array}$ \\
\hline 0 & 585 & 400 & 320 & 822 \\
\hline 0.2 & 585 & 477 & 320 & 880 \\
\hline 0.4 & 578 & 504 & 324 & 854 \\
\hline 0.6 & 580 & 509 & 324 & 809 \\
\hline 0.8 & 584 & 509 & 325 & 880 \\
\hline 1 & 595 & 509 & 325 & 869 \\
\hline
\end{tabular}


The force constants of the tetrahedral site $F_{A}$ and the octahedral site $F_{B}$ depend on the vibrational frequency and is calculated from the relation [19]:

$$
F_{A}=4 \pi^{2} c^{2} v_{1}^{2} \mu, F_{B}=4 \pi^{2} c^{2} v_{2}^{2} \mu
$$

"where $\mu$ is the reduced mass of $\mathrm{Fe}^{3+}$ and $\mathrm{O}^{2-}$ ions $\left(\mu=2.061 \times 10^{-23} \mathrm{~g}\right)$ " [20] and $c$ is the velocity of the electromagnetic wave $\left(c=3 \times 10^{10} \mathrm{~cm} / \mathrm{s}\right)$. The force constant is proportional to the strength of the bonds between the ions. As mentioned above, the bond length shortens by replacing $\mathrm{Fe}^{3+}$ ions by $\mathrm{Cr}^{3+}$ ions at the octahedral sites which leads to raising the force constant $\left(F_{B}\right)$, as shown in Fig.(3).

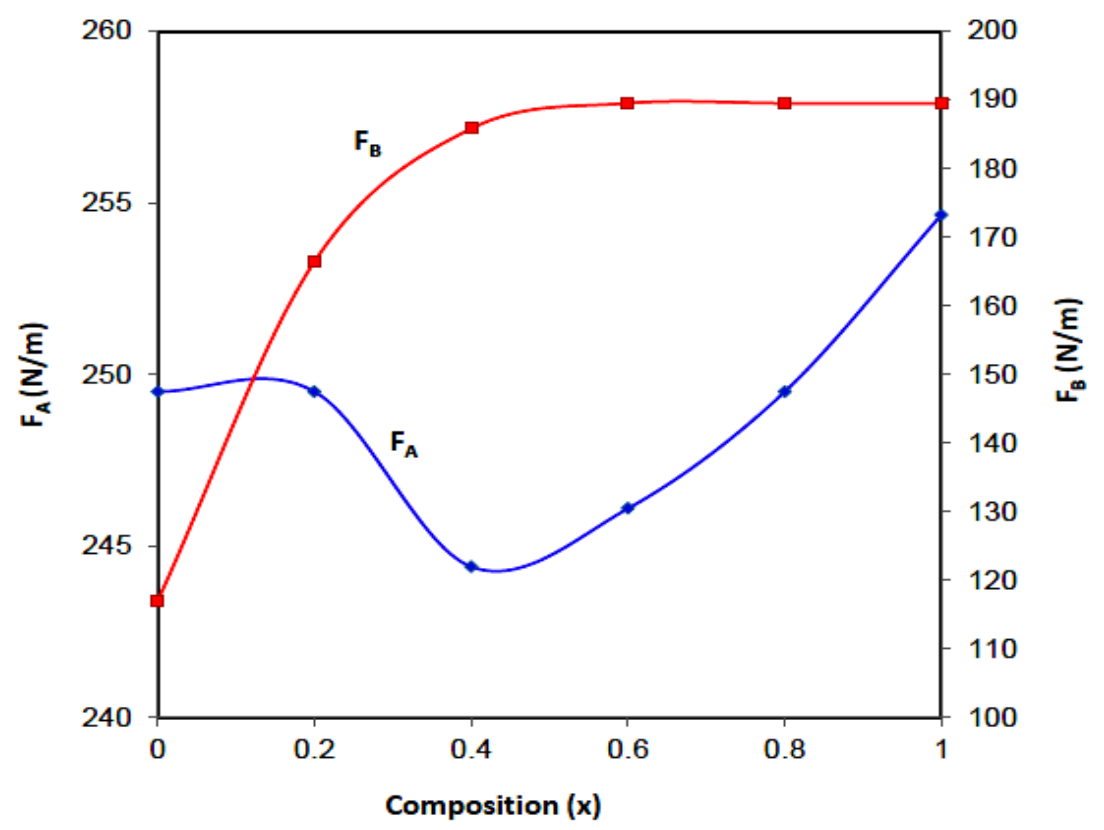

Figure (3): The relation between the force constants and the composition.

Debye temperature $\theta_{D}$ is the temperature at which a crystal has its highest normal mode of vibration. It is calculated using the relation $\theta_{D}=\frac{h c v_{A V}}{2 \pi k}[21]$, where $h$ is Plank's constant, $k$ is Boltzmann's constant, $\mathrm{c}$ is the velocity of light and $v_{A V}$ is the average value of the wavenumbers which equals $\left(v_{1}+v_{2}\right) / 2$. The calculated $\theta_{D}$ is drawn as a function of the composition ' $x$ ', as displayed in Fig. (4).

Debye temperature specifies the stability of the crystal lattice. When the material is heated below Debye temperature, the atomic motion is restricted, and the electrons move across the lattice planes with minimal scattering. But above Debye temperature, the scattering becomes quite large [21]. So materials with higher Debye temperature have low scattering and hence become more stable. In these samples, $\theta_{D}$ increases with $x$ as seen because the strength of interatomic bonding hardens, which indicates that the lattice becomes more stable by increasing $\mathrm{Cr}^{3+}$ ions [21]. 


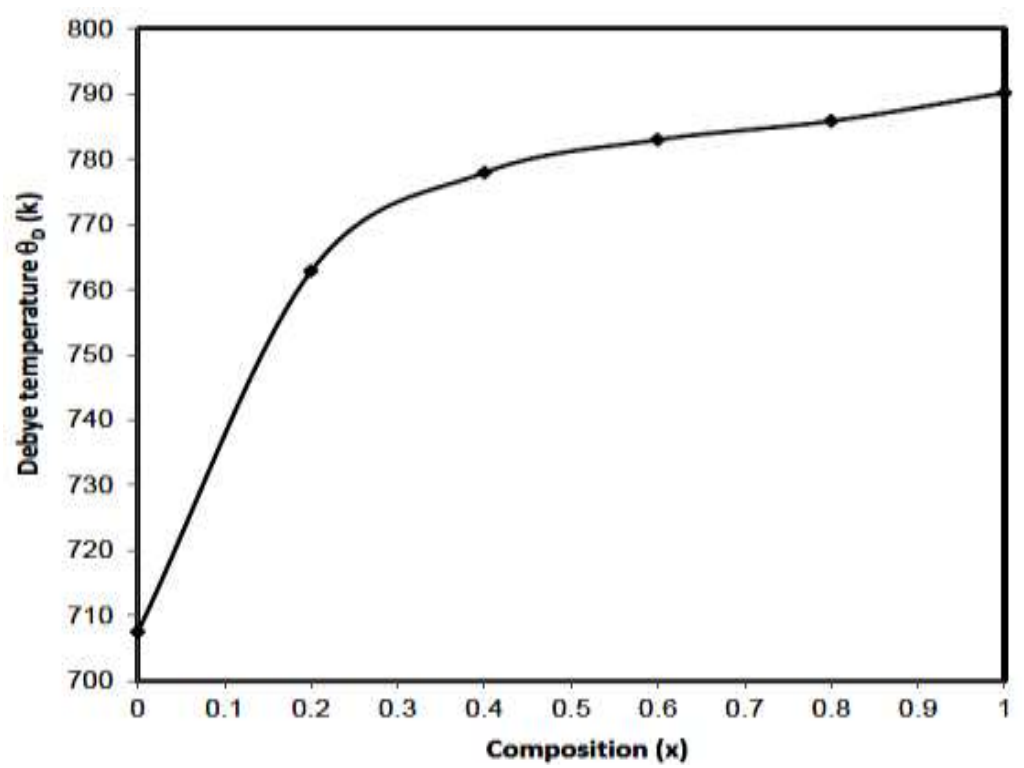

Figure (4): Debye temperature $\theta_{D}$ as a function of composition.

\subsection{Elastic properties}

The elastic constants clarify the nature of the binding forces and the thermal properties of solids. Especially, Young's modulus of ferrite materials is a critical agent for the various magnetic core shapes as rods and rings [22]. Some effective factors as high magnetic field, electric field, pressure, or temperature can generate large stresses in a polycrystalline material. The mechanical properties are of prominent importance in the incorporation of the material into a functional device [22].

It is worth mentioning that the ultrasonic pulse transmission technique (UPT) is a common technique for measuring the elastic and force constants of materials. In this technique, the length of the tested material should be about 1 $\mathrm{cm}$, and the sample must be in the hard pelletized shape. This seems difficult because novel advanced materials such as nanoparticles, single crystals or irradiated material can be synthesized in very small quantities. So UPT is considered as a complicated technique [23]. Therefore, FTIR spectroscopy is a preferable technique for measuring the mechanical properties in such cases because it is sufficient to use only few milligrams of a material for IR examination. Furthermore, in UPT technique, the influence of pores and microcracks should be frustrated by zero porosity correction. But it is not required in infrared spectroscopy [23].

For cubic structured materials, the force constant $\left(F_{c}\right)$ equals the product of stiffness constant $\left(C_{1 l}\right.$ longitudinal modulus) and lattice constant $(a)$. The stiffness elastic constants, $C_{11}$ and $C_{12}$ are calculated using the following relations [24]: 


$$
C_{11}=\frac{F_{C}}{a}, C_{12}=\frac{\sigma C_{11}}{(1-\sigma)}
$$

$\sigma$ is the Poisson's ratio that is a function of pore fraction: $\sigma=0.324(1-1.043 P)$, where $P$ is the porosity. Also, the three elastic moduli of solids for cubic structure in terms of stiffness constants are calculated using the following relations [25]:

$$
\begin{aligned}
& \text { Bulk modulus }(B)=\frac{1}{3}\left(C_{11}+2 C_{12}\right) \\
& \text { Young's modulus }(E)=\frac{\left(C_{11}-C_{12}\right)\left(C_{11}+2 C_{12}\right)}{\left(C_{11}+C_{12}\right)} \\
& \text { Rigidity modulus }(G)=\frac{E}{2(\sigma+1)}
\end{aligned}
$$

Increasing the proportion of $\mathrm{Cr}^{3+}$ ions raises the elastic moduli values, as seen in Table 3, because minimizing the grain size leads to the excessive increase in the total grain boundary area which contributes to the rigidity of the materials. Grain boundaries play a significant role in dislocation motion impedance. Since the existence of dislocations weakens the crystal then minimization of the grains enhances the strength as well as the toughness of materials [24] [23]. Generally, elastic moduli of nano-crystalline ferrites are larger than their bulk counterparts according to the literature [26].

Table (3): Stiffness constants, $C_{11}, C_{12}$, elastic moduli, $B, Y$ and $G$.

\begin{tabular}{|c|c|c|c|c|c|}
\hline $\mathrm{X}$ & $C_{11}(\mathrm{GPa})$ & $C_{12}(\mathrm{GPa})$ & $B(\mathrm{GPa})$ & $Y(\mathrm{GPa})$ & $G(\mathrm{GPa})$ \\
\hline 0 & 217.4 & 384.1 & 98.07 & 205.8 & 89.48 \\
\hline 0.2 & 247.6 & 435 & 111.5 & 234.6 & 102.1 \\
\hline 0.4 & 256.4 & 458.9 & 116 & 242.4 & 105.2 \\
\hline 0.6 & 259.9 & 474 & 118.2 & 245.3 & 106.3 \\
\hline 0.8 & 262.3 & 484.5 & 119.7 & 247.2 & 106.9 \\
\hline 1 & 268.3 & 502.2 & 122.9 & 252.5 & 109 \\
\hline
\end{tabular}

\subsection{Transmission Electron Microscopy (TEM):}

Figure (5) shows the TEM micrographs of $\mathrm{Co}_{0.7} \mathrm{Mn}_{0.3} \mathrm{Cr}_{\mathrm{x}} \mathrm{Fe}_{2-\mathrm{x}} \mathrm{O}_{4}(\mathrm{x}=0$, $0.2,0.4,1)$ ferrite nanoparticles. The measured size of the nano-crystals from TEM images is in good agreement with the size calculated from peak broadening in X-ray diffractograms, as listed in Table $1 . \mathrm{Cr}^{3+}$ ions effect on the particle size is very clear. The histograms of the size distribution obtained from the statistics over around 230 particles show that the particles have a narrow size distribution as in Fig. (6). Most of the particles have nearly spherical appearance however some elongated particles are also present. The selected area electron diffraction (SAED) pattern of $\mathrm{Co}_{0.7} \mathrm{Mn}_{0.3} \mathrm{Fe}_{2} \mathrm{O}_{4}$ is shown in Fig. 5(b). The SAED pattern consists of concentric rings with bright spots over the rings. This feature indicates that the samples are polycrystalline. High crystallinity of $\mathrm{Co}_{0.7} \mathrm{Mn}_{0.3} \mathrm{Fe}_{2} \mathrm{O}_{4}$ was proven by the spotted look of the diffraction rings, as expected. 

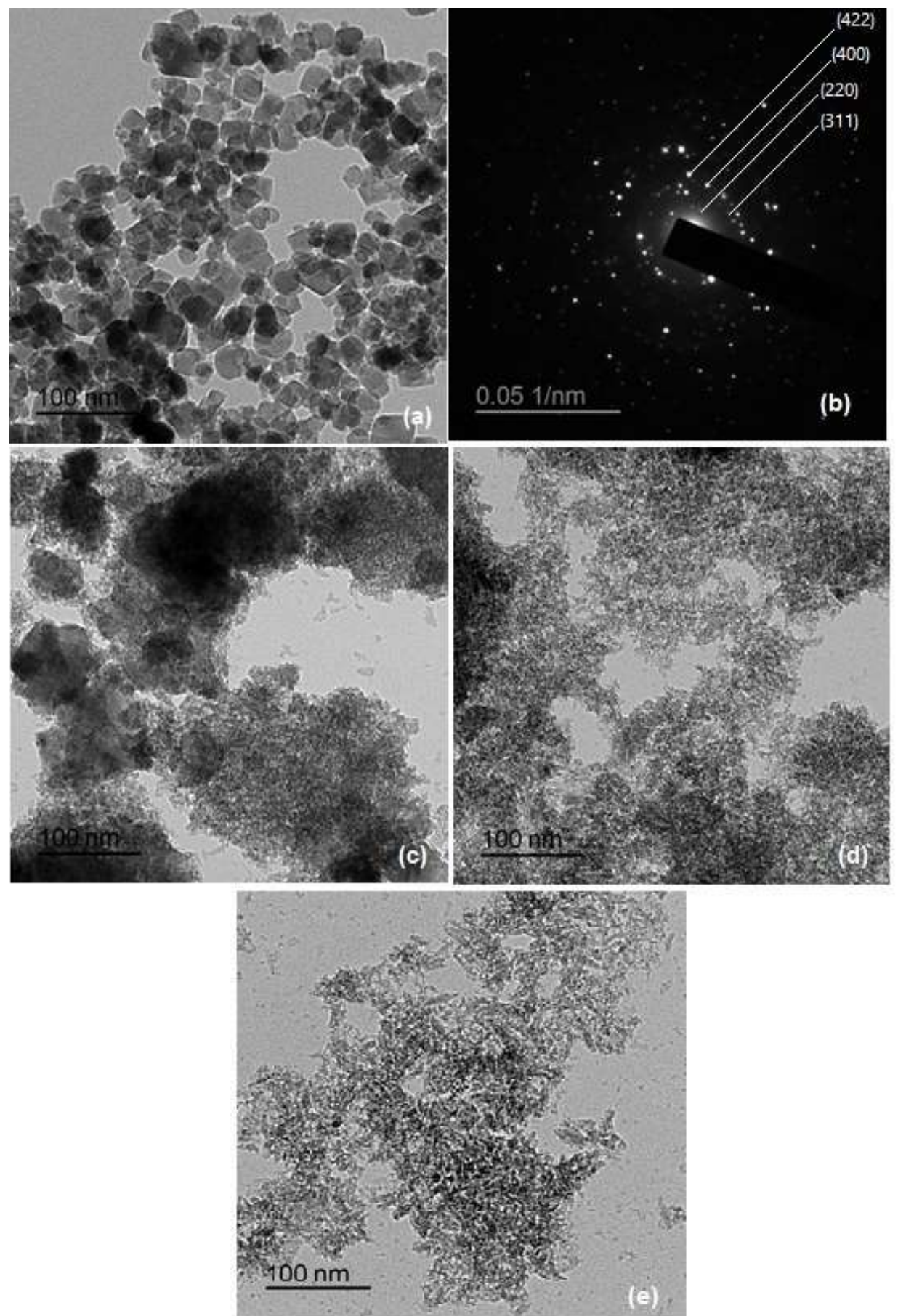

Figure (5): TEM images of: (a), (b) $\mathrm{Co}_{0.7} \mathrm{Mn}_{0.3} \mathrm{Fe}_{2} \mathrm{O}_{4}$, its SAED pattern respectively (c) $\mathrm{Co}_{0.7} \mathrm{Mn}_{0.3} \mathrm{Cr}_{0.2} \mathrm{Fe}_{1.8} \mathrm{O}_{4}$ (d) $\mathrm{Co}_{0.7} \mathrm{Mn}_{0.3} \mathrm{Cr}_{0.4} \mathrm{Fe}_{1.6} \mathrm{O}_{4}$ (e) $\mathrm{Co}_{0.7} \mathrm{Mn}_{0.3} \mathrm{CrFeO}_{4}$. 

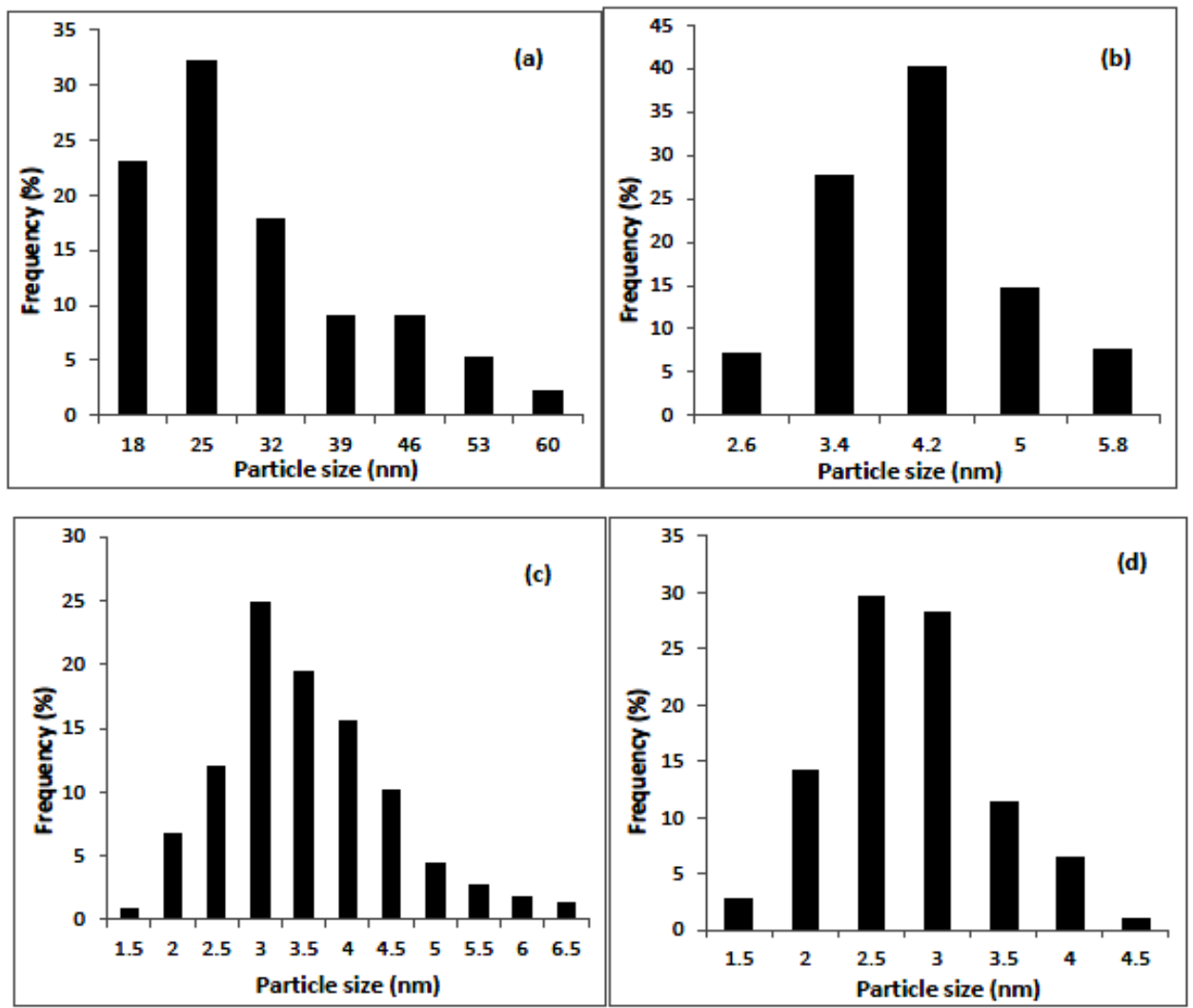

Figure (6): Particle size distribution of: (a) $\mathrm{Co}_{0.7} \mathrm{Mn}_{0.3} \mathrm{Fe}_{2} \mathrm{O}_{4}$ (b) $\mathrm{Co}_{0.7} \mathrm{Mn}_{0.3} \mathrm{Cr}_{0.2} \mathrm{Fe}_{1.8} \mathrm{O}_{4}$ (c) $\mathrm{Co}_{0.7} \mathrm{Mn}_{0.3} \mathrm{Cr}_{0.4} \mathrm{Fe}_{1.6} \mathrm{O}_{4}$ (d) $\mathrm{Co}_{0.7} \mathrm{Mn}_{0.3} \mathrm{CrFeO}_{4}$.

\subsection{Ultraviolet and Visible Spectroscopy:}

The optical absorption spectra of $\mathrm{Co}_{0.7} \mathrm{Mn}_{0.3} \mathrm{Cr}_{\mathrm{x}} \mathrm{Fe}_{2-\mathrm{x}} \mathrm{O}_{4}$ samples in the visible and ultraviolet regions are shown in Fig. (7). The overall behavior of the absorbance spectra is the same for all the samples, and the absorbance has been reduced with increasing $\mathrm{Cr}^{3+}$ ion ratio. The dependence of absorbance on wavelength is negligible for small sizes [14].

The energy band-gaps have been calculated with the help of optical absorption data. The absorption coefficient, ' $\alpha$ ' has been calculated using the fundamental relations: $I=I_{0} e^{-\alpha t},=\operatorname{Ln}\left(\frac{I}{I_{0}}\right)=-\alpha t$, where $A$ is the absorbance and, $t$ is the thickness of the sample. In the high-absorption intensity region, the optical absorption coefficient follows the known Beer-Lambert law: $\alpha h v=\beta(h v$ $\left.-E_{g}\right)^{n}$. To estimate the energy band-gap $\left(E_{g}\right)$, the graph of $(\alpha h v)^{2}$ versus $h v$ has been plotted (not displayed here). The intercept of the line at $\alpha=0$ gives the values of $\left(E_{g}\right)$. The values have been found in the range 1.382-2.229 eV (Table 4). The features of crystalline solids such as the structure and the defects affect deeply the band-gap [27]. It is observed that the energy band-gap expands by 
reducing the particle size [28] so a blue shift occurs in the absorption spectra, as seen in Fig. (7). This means that the electrons need more energy to cross the larger forbidden band in tiny size samples which exhibit lower electrical conductivity, as will be discussed below.

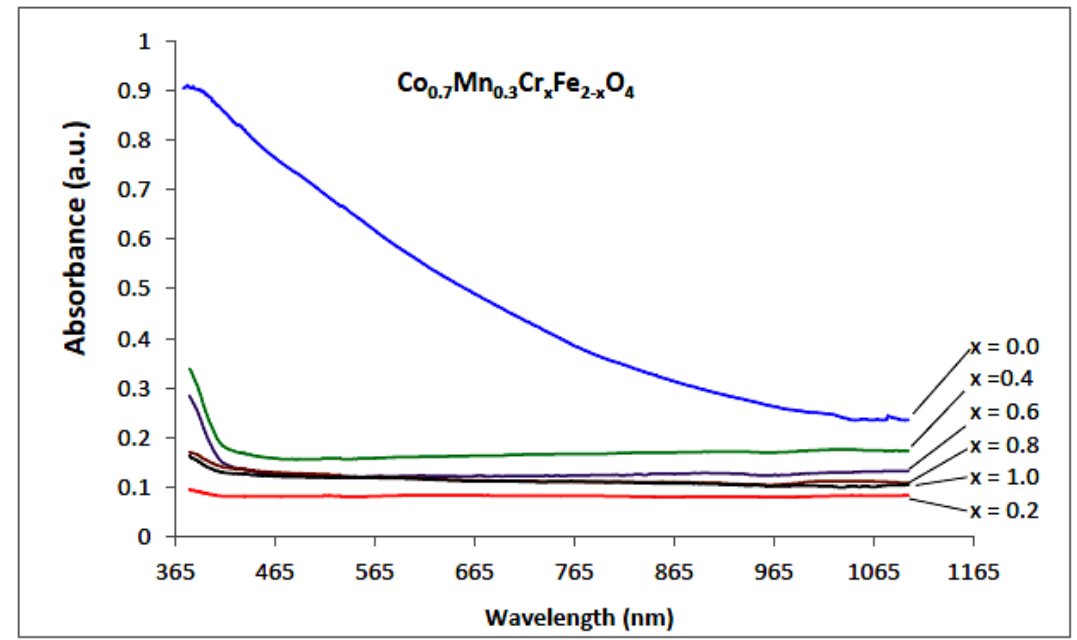

Figure (7): UV/Visible absorption spectra of $\mathrm{Co}_{0.7} \mathrm{Mn}_{0.3} \mathrm{Cr}_{\mathrm{x}} \mathrm{Fe}_{2-\mathrm{x}} \mathrm{O}_{4}$ samples.

The values of the exponent $\mathrm{n}$ depend on the nature of the transition and are theoretically equal to 2 and $1 / 2$ for allowed indirect and direct electronic transition, respectively [29]. Transferring electrons from the highest-energy state in the valence band to the lowest one in the conduction band without any variation in momentum makes the band-gap "direct" and consequently photons can be emitted. While in the "indirect" band-gap, the crystal momentum changes and a photon cannot be emitted because the electron must pass through a moderate state and transfer momentum to the crystal lattice [30].

The analysis of the obtained data shows that the involved transition mechanism is the allowed direct transition since linearity dependence is obtained with $n=1 / 2$. It is worth mentioning that the variation of the band-gap with varying the particle size is an important aspect for photocatalytic applications of these materials [31].

Table (4): The optical energy-gap, $\mathrm{E}_{\mathrm{g}}$ of $\mathrm{Co}_{0.7} \mathrm{Mn}_{0.3} \mathrm{Cr}_{\mathrm{x}} \mathrm{Fe}_{2-\mathrm{x}} \mathrm{O}_{4}$ samples.

\begin{tabular}{|l|c|}
\hline \multicolumn{1}{|c|}{ Samples } & $\boldsymbol{E}_{\boldsymbol{g}}(\mathbf{e V})$ \\
\hline $\mathrm{Co}_{0.7} \mathrm{Mn}_{0.3} \mathrm{Fe}_{2} \mathrm{O}_{4}$ & 1.382 \\
\hline $\mathrm{Co}_{0.7} \mathrm{Mn}_{0.3} \mathrm{Cr}_{0.2} \mathrm{Fe}_{1.8} \mathrm{O}_{4}$ & 1.903 \\
\hline $\mathrm{Co}_{0.7} \mathrm{Mn}_{0.3} \mathrm{Cr}_{0.4} \mathrm{Fe}_{1.6} \mathrm{O}_{4}$ & 2.731 \\
\hline $\mathrm{Co}_{0.7} \mathrm{Mn}_{0.3} \mathrm{Cr}_{0.6} \mathrm{Fe}_{1.4} \mathrm{O}_{4}$ & 2.74 \\
\hline $\mathrm{Co}_{0.7} \mathrm{Mn}_{0.3} \mathrm{Cr}_{0.8} \mathrm{Fe}_{1.2} \mathrm{O}_{4}$ & 2.229 \\
\hline $\mathrm{Co}_{0.7} \mathrm{Mn}_{0.3} \mathrm{Cr}_{1} \mathrm{Fe}_{1} \mathrm{O}_{4}$ & 2.325 \\
\hline
\end{tabular}




\subsection{Magnetic Measurements:}

The magnetic hysteresis loop is formed by applying a variable magnetic field through the sample and measuring its magnetization. In Co ferrites, the magnetic anisotropy and hysteresis are obviou. The magnetic hysteresis loops of the $\mathrm{Co}_{0.7} \mathrm{Mn}_{0.3} \mathrm{Cr}_{\mathrm{x}} \mathrm{Fe}_{2-\mathrm{x}} \mathrm{O}_{4}$ samples are displayed in Fig. (8).

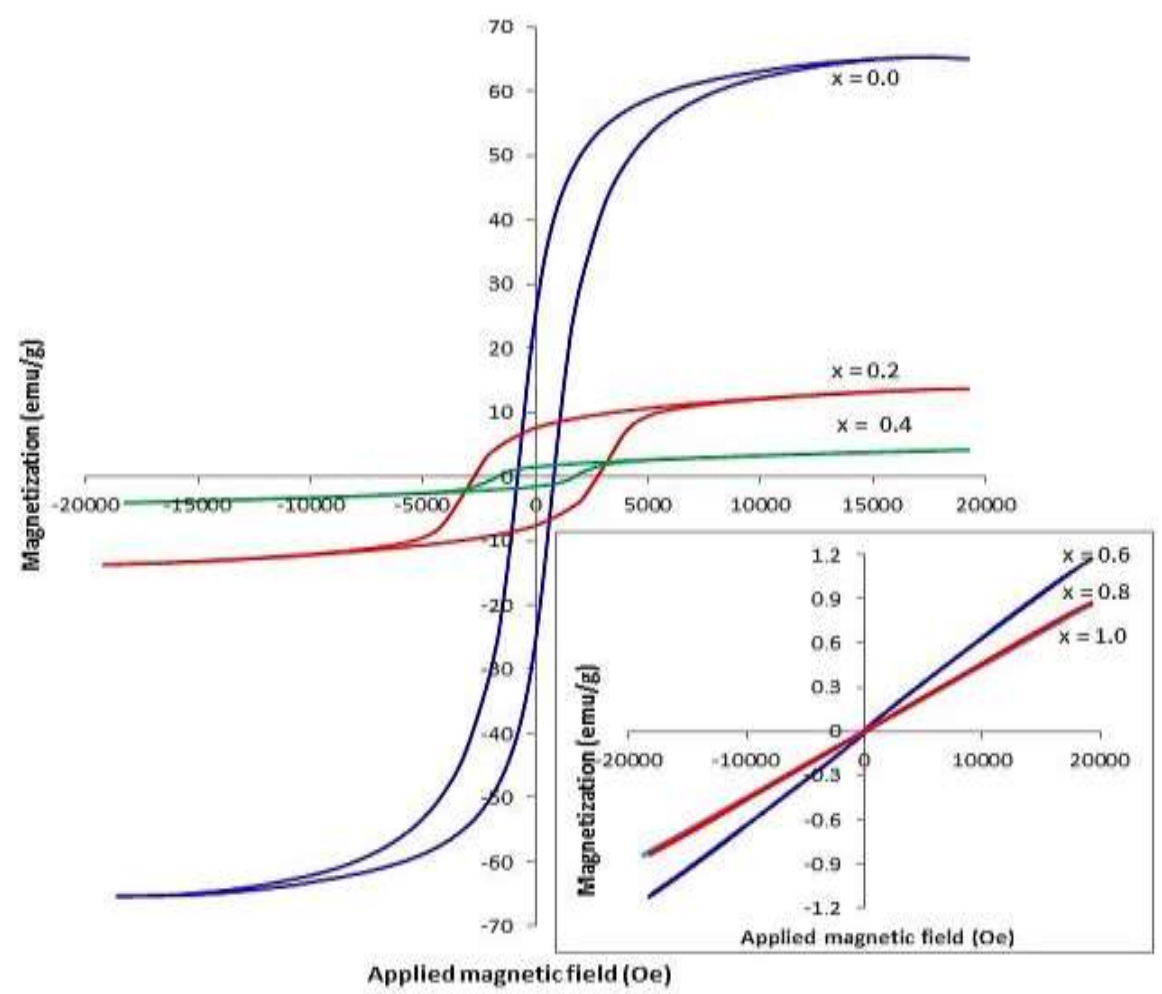

Figure (8): The magnetic hysteresis loops of the $\mathrm{Co}_{0.7} \mathrm{Mn}_{0.3} \mathrm{Cr}_{\mathrm{x}} \mathrm{Fe}_{2-\mathrm{x}} \mathrm{O}_{4}$ nanoparticles.

Table (5): values of saturation magnetization $M_{s}$, remnant magnetization $M_{r}$, squareness ratio SQR and coercivity $H_{c}$ of $\mathrm{Co}_{0.7} \mathrm{Mn}_{0.3} \mathrm{Cr}_{\mathrm{x}} \mathrm{Fe}_{2-\mathrm{x}} \mathrm{O}_{4}$ samples.

\begin{tabular}{|l|c|c|c|c|}
\hline Sample & $\mathbf{M}_{\mathbf{s}}(\mathbf{e m u} / \mathbf{g})$ & $\mathbf{M}_{\mathbf{r}}(\mathbf{e m u} / \mathbf{g})$ & $\mathbf{M}_{\mathbf{r}} / \mathbf{M}_{\mathbf{s}}$ & $\mathbf{H}_{\mathbf{c}}(\mathbf{G})$ \\
\hline $\mathrm{X}=0$ & 65.407 & 25.340 & 0.387 & 806.33 \\
\hline $\mathrm{X}=0.2$ & 13.693 & 7.5887 & 0.554 & 2736.5 \\
\hline $\mathrm{X}=0.4$ & 4.1230 & 1.5289 & 0.371 & 1723.2 \\
\hline $\mathrm{X}=0.6$ & ------- & ------- & ------ & 151.68 \\
\hline $\mathrm{X}=0.8$ & ------- & ------- & ------ & 5.2228 \\
\hline $\mathrm{X}=1$ & -------- & ------- & ------ & 4.3324 \\
\hline
\end{tabular}

The presence of $\mathrm{Cr}^{3+}$ ions at the octahedral sites causes a rapid drop in the saturation magnetization $\left(M_{s}\right)$ values, as seen in Table (5). So the magnetization of the octahedral site $\left(M_{B}\right)$ decreases while the magnetization of the tetrahedral site $\left(M_{A}\right)$ increases. Therefore the net magnetization $\left(M_{B}-M_{A}\right)$ decreases [15]. 
Moreover, uncompensated spins form at the surface of the nanoparticles and reduce $\mathrm{M}_{\mathrm{s}}$ [1] [7]. The saturation magnetization of $\mathrm{CoFe}_{2} \mathrm{O}_{4}$ can be improved by adding ions with higher magnetic moment than cobalt as manganese where $\mathrm{Co}^{2+}$ is $3 \mu_{\mathrm{B}}$ but $\mathrm{Mn}^{2+}$ is $5 \mu_{\mathrm{B}}$ [11]. The unsaturated magnetization of $\mathrm{Co}_{0.7} \mathrm{Mn}_{0.3} \mathrm{Cr}_{\mathrm{X}} \mathrm{Fe}_{2-}$ ${ }_{\mathrm{x}} \mathrm{O}_{4}(\mathrm{x} \geq 0.6)$ is due to thermal fluctuations of small particles at room temperature even at the maximum field of $20 \mathrm{kOe}$. These small particles have large surface with disordered spins that leads to non-saturated magnetization [32]. The samples $\mathrm{Co}_{0.7} \mathrm{Mn}_{0.3} \mathrm{Cr}_{\mathrm{x}} \mathrm{Fe}_{2-\mathrm{x}} \mathrm{O}_{4} \quad(\mathrm{x} \geq 0.6)$ exhibit non-hysteresis state and may be considered as superparamagnetics which have several applications, such as drug delivery, hyperthermia, bio-separation, and magnetic resonance imaging. The nearly zero coercive force permits easy magnetization and demagnetization with little magnetic loss. Therefore, those soft magnetic materials may be suitable for transformer and motor cores to reduce the energy dissipation with $\mathrm{AC}$ alternating fields [33].

The existence of non-magnetic $\mathrm{Cr}^{3+}$ ions minimizes the coercivity because of reducing the anisotropy field, which in turn decreases the domain wall energy [15]. It is seen that the squareness ratio $\left(M_{r} / M_{s}\right)$ of the sample $\mathrm{Co}_{0.7} \mathrm{Mn}_{0.3} \mathrm{Cr}_{0.2} \mathrm{Fe}_{1.8} \mathrm{O}_{4}$ is relatively high. Generally, large SQR values are desired for recording medium [26]. While the other samples with lower SQR may be used as choke coils to reduce high frequency harmonics in the current source. This requires a soft magnetic material with induced anisotropy and low remanence [1].

The dependence of coercivity on the particle size is clarified based on domain structure. From Table (1) and Table (5), it is observed that the coercivity increases with the particle size up to its highest value of 2736.5 Gauss for the sample $\mathrm{x}=0.2$ which has a single domain size limit [34]. After that $\mathrm{H}_{\mathrm{c}}$ decreases for the sample $\mathrm{x}=0.0$ due to the formation of multi-domains.

The magneto-crystalline anisotropy constant $K_{l}$, which is proportional to $H_{c}$ and $M_{s}$ by the formula: $H_{c} \alpha \frac{K_{1}}{M_{s}}$, decreases by decreasing the coercivity. The magnetic fine particles containing cobalt exhibit cubic anisotropy or uniaxial magnetic anisotropy. The type of anisotropy depends on the squareness ratio $M_{r} / M_{s}$ [35] according to the Stoner-Wohlfarth model for single domain particles oriented randomly [36]. When $\mathrm{M}_{\mathrm{r}} / \mathrm{M}_{\mathrm{s}} \leq 0.5$ the anisotropy is uniaxial magnetic anisotropy rather than cubic anisotropy. So we can deduce that the samples $\mathrm{Co}_{0.7} \mathrm{Mn}_{0.3} \mathrm{Cr}_{x} \mathrm{Fe}_{2-\mathrm{x}} \mathrm{O}_{4}$ with $\mathrm{x} \leq 0.4$ possess uniaxial anisotropy which can be caused by surface effects [36].

On the other hand, the magnetization is always decreasing as porosity increases contrary to the coercivity which increases with porosity in some cases and decreases in others. Fig. (9), displays the increase of $H_{c}$ with the porosity because the acicularity of inner pores is larger than the magnetic particles [37]. 


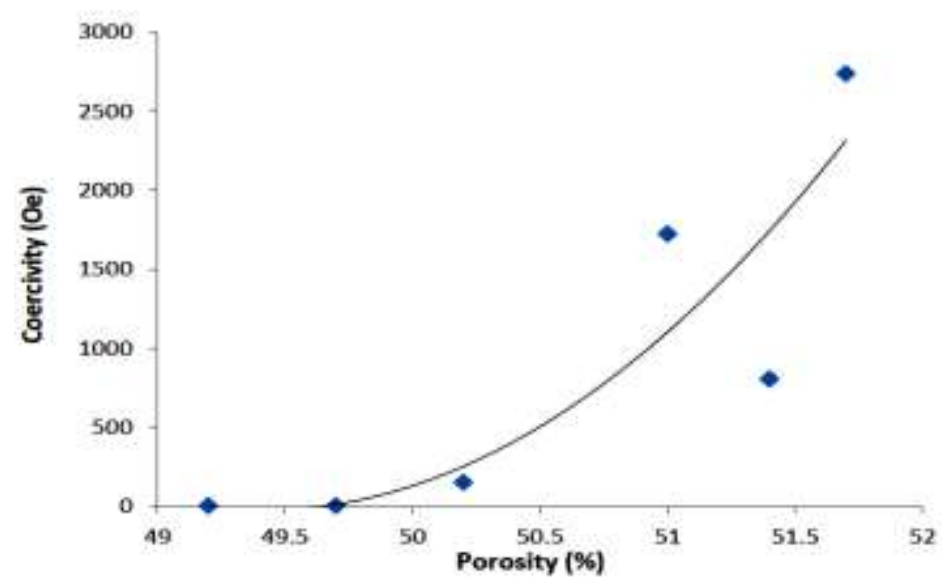

Figure (9): Variation of coercivity with porosity

\subsection{Electrical Conductivity:}

The DC electrical conductivity $\left(\sigma_{d c}\right)$ is given by the well-known relation:

$$
\sigma=\sigma_{0} e^{-E_{a} / K T}
$$

where $\sigma_{0}$ is the pre-exponential factor and, $E_{a}$ is the activation energy. While the drift mobility, $\mu_{d}$ could be calculated using the relations [38]:

$$
\mu_{d}=\frac{1}{n \theta \rho}, n=\frac{N \rho_{m}}{M} P_{F \theta}
$$

where $e$ is the charge of the electron, $\rho$ is the resistivity, $n$ is the concentration of charge carriers, $N$ is the Avogadro's number, $M$ is the molecular weight of the compound, $P_{F e}$ is the number of iron atoms in the chemical formula of the ferrites and $\rho_{m}$ is the measured density. Raising temperature increases the drift mobility of the electric charge carriers that leads to increasing conductivity, as seen in Fig. (10:11), reflects the semiconducting nature of ferrites.

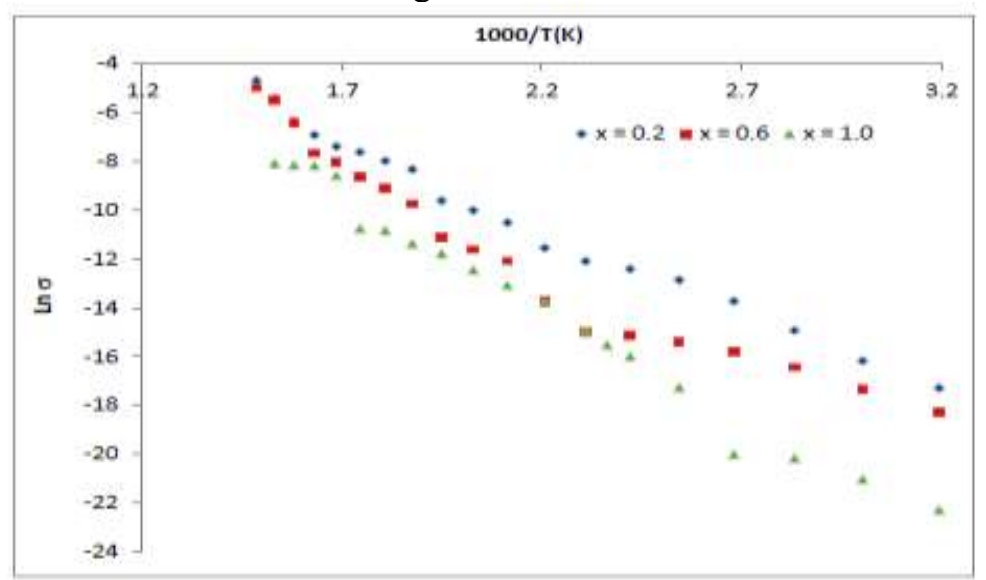

Figure (10): DC conductivity of some selected $\mathrm{Co}_{0.7} \mathrm{Mn}_{0.3} \mathrm{Cr}_{\mathrm{x}} \mathrm{Fe}_{2-\mathrm{x}} \mathrm{O}_{4}$ samples. 


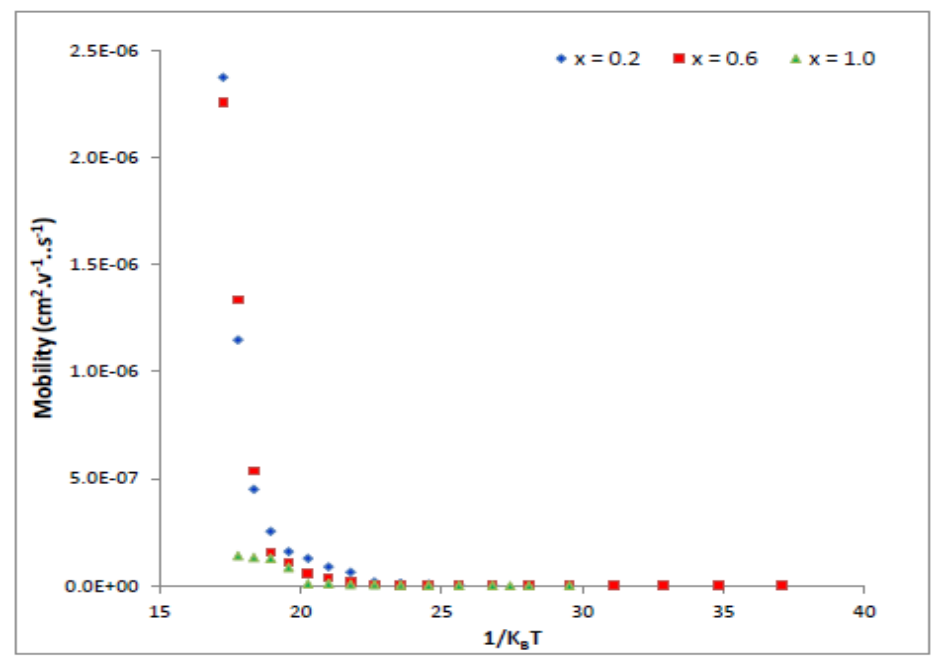

Figure (11): Drift mobility as a function of inverse temperature $\left(1 / \mathrm{k}_{\mathrm{B}} \mathrm{T}\right)$.

Hopping of charge carriers between ions (i. e. $\mathrm{Fe}^{2+}-\mathrm{Fe}^{3+}$ ) of different valance states is considered as the main conduction mechanism in ferrites [39]. The hopping chance depends on the distance (jump length) through which the electrons pass between different valance states of metal. So it is expected that electron hopping probability increases by shortening the jump length. Actually the jump length decreased in the samples, as seen in Table 1 but the hopping conductivity decreases. This happened because replacing $\mathrm{Fe}^{3+}$ ions by $\mathrm{Cr}^{3+}$ ions in the octahedral sites reduces the hopping probability of the $3 \mathrm{~d}$ electrons between $\mathrm{Fe}^{2+}$ and $\mathrm{Fe}^{3+}$ [14]. Hopping takes place among electrons in octahedral sites because the distance between two metal ions in the octahedral site is shorter than that between the octahedral and tetrahedral sites [26], as shown in Table (1).

The activation energy was determined using the known Arrhenius relation. The activation energy values vary with temperature by changing the conduction mechanism, as shown in Table 6. The activation energy at higher temperature region is higher than that at lower temperature region. The electric conduction at lower temperatures is due to electron hopping between $\mathrm{Fe}^{2+}$ and $\mathrm{Fe}^{3+}$ ions, whereas at higher temperatures, it is due to hopping of small polarons [40]. A small polaron is formed when a charge is captured at a certain site and, the neighboring ions are displaced towards this charge creating distortion. Both the charge and its distortion together are called a polaron. Naturally, the movement of the polaron takes place at higher temperatures by thermally activated hopping mechanism [21].

Table 6: The activation energy (eV) of $\mathrm{Co}_{0.7} \mathrm{Mn}_{0.3} \mathrm{Cr}_{\mathrm{x}} \mathrm{Fe}_{2-\mathrm{x}} \mathrm{O}_{4}$ samples.

\begin{tabular}{|c|c|c|c|}
\hline $\mathrm{X}$ & $\mathrm{x}=0.2$ & $\mathrm{x}=0.6$ & $\mathrm{x}=1$ \\
\hline \multicolumn{4}{|c|}{ Activation energy $E_{a}(\mathrm{eV})$} \\
\hline Low temperature region & 0.512 & 0.327 & 0.391 \\
\hline High temperature region & 0.757 & 0.988 & 0.814 \\
\hline
\end{tabular}


It is worth mentioning that we should distinguish between the electrical conduction activation energy $E_{a}$ and the optical band-gap $E_{g}$. $E_{a}$ depends on the energy required to overcome the Coulomb interactions between electrons and their atoms whereas $E_{g}$ means the energy needed for excitation of electrons from the valance band to conduction band using photons of selected frequency [41]. So it is expected to find $E_{g}>E_{a}$ as shown in Tables 4, 6 .

\section{Conclusion}

The obtained ferrite nano-particles synthesized by the co-precipitation method have narrow range of particle sizes which has been confirmed by TEM analysis. The substitution of $\mathrm{Cr}^{3+}$ ions plays a significant role in the alternation of crystal structure, morphologies and physical properties. The infrared spectroscopy is a successful and powerful technique for calculating the force constants and elastic moduli. $\mathrm{Cr}^{3+}$ ions substitution hardens the interatomic bonding and, enhances the stability of the lattice. Superparamagnetic $\mathrm{Co}_{0.7} \mathrm{Mn}_{0.3} \mathrm{Cr}_{\mathrm{x}} \mathrm{Fe}_{2-\mathrm{x}} \mathrm{O}_{4}$ $(\mathrm{x} \geq 0.6)$ nanocrystals are believed to be promising in drug delivery, hyperthermia, bio-separation, and magnetic resonance imaging. The nearly zero coercive force makes these soft magnetic materials to be suitable for the low-loss applications. The high squareness ratio $\left(\mathrm{M}_{\mathrm{r}} / \mathrm{M}_{\mathrm{s}}\right)$ of $\mathrm{Co}_{0.7} \mathrm{Mn}_{0.3} \mathrm{Cr}_{0.2} \mathrm{Fe}_{1.8} \mathrm{O}_{4}$ makes it desirable for recording media, while lower squareness samples may be used in cores of choke coils. The samples $\mathrm{Co}_{0.7} \mathrm{Mn}_{0.3} \mathrm{Cr}_{\mathrm{x}} \mathrm{Fe}_{2-\mathrm{x}} \mathrm{O}_{4}$ with $\mathrm{x} \leq 0.4$ have uniaxial anisotropy.

\section{Acknowledgements:}

This work is financially supported by Tanta University.

\section{References}

1. P. Grunberg, nanoscale Magnetic Materials and Applications, 2 nd eddit, Springer, USA, 2009.

2. D. Menzel, A. Feldhoff, V. Šepelák, J. Amighian, M. Myndyk, M.J. Nasr Isfahani, Magnetic properties of nanostructured MnZn ferrite, J. Magn. Magn. Mater. 321 (2008) 152-156. doi:10.1016/j.jmmm.2008.08.054.

3. S.H. Hosseini, A. Asadnia, Synthesis, Characterization, and MicrowaveAbsorbing Properties of Polypyrrole/MnFe2O4 Nanocomposite, J. Nanomater. 2012 (2012) 1-6. doi:10.1155/2012/198973.

4. M.B. Mohamed, A.M. Wahba, M. Yehia, Structural and magnetic properties of CoFe2-xMoxO4 nanocrystalline ferrites, Mater. Sci. Eng. B. 190 (2014) 52-58. doi:10.1016/j.mseb.2014.09.010.

5. R.L. Dhiman, S.P. Taneja, V.R. Reddy, Preparation and Characterization of Manganese Ferrite Aluminates, Adv. Condens. Matter Phys. 2008 (2008) 17. doi:10.1155/2008/703479. 
6. K.P. Chae, Y.B. Lee, J.G. Lee, S.H. Lee, Crystallographic and magnetic properties of $\mathrm{CoCrxFe2-xO4ferrite} \mathrm{powders,} \mathrm{J.} \mathrm{Magn.} \mathrm{Magn.} \mathrm{Mater.} 220$ (2000) 59-64. doi:10.1016/S0304-8853(00)00459-5.

7. E.H. El-Ghazzawy, S.N. Alamri, NiCrxFe2-xO4 ferrite nanoparticles and their composites with polypyrrole: Synthesis, characterization and magnetic properties, Bull. Mater. Sci. 38 (2015) 915-924.

8. H.A. Badehian, H. Salehi, M. Ghoohestani, First-principles study of elastic, structural, electronic, thermodynamical, and optical properties of Yttria (Y2O3) ceramic in cubic phase, J. Am. Ceram. Soc. 96 (2013) 1832-1840. doi:10.1111/jace.12259.

9. M.A. Amer, A. Matsuda, G. Kawamura, R. El-Shater, T. Meaz, F. Fakhry, Characterization and structural and magnetic studies of as-synthesized Fe2+CrxFe(2-x)O4 nanoparticles, J. Magn. Magn. Mater. 439 (2017) $373-$ 383. doi:10.1016/j.jmmm.2017.05.048.

10. M. Raghasudha, D. Ravinder, $\mathrm{P}$. Veerasomaiah, Magnetic properties of $\mathrm{Cr}-$ substituted Co-ferrite nanoparticles synthesized by citrate-gel autocombustion method, J. Nanostructure Chem. 3 (2013) 63. doi:10.1186/2193-8865-3-63.

11. A. Manikandan, M. Durka, S.A. Antony, A Novel Synthesis, Structural, Morphological, and Opto-magnetic Characterizations of Magnetically Separable Spinel CoxMn1-xFe2O4 $(0 \leq \mathrm{x} \leq 1)$ Nano-catalysts, J. Supercond. Nov. Magn. 27 (2014) 2841-2857. doi:10.1007/s10948-014-2771-1.

12. E.H. El-Ghazzawy, M.A. Amer, Structural, elastic and magnetic studies of the as-synthesized Co1-x Srx Fe2O4 nanoparticles, J. Alloys Compd. 690 (2016) 293-303. doi:10.1016/j.jallcom.2016.08.135.

13. B. Parvatheeswara Rao, O. Caltun, W.S. Cho, C.O. Kim, C.G. Kim, Synthesis and characterization of mixed ferrite nanoparticles, J. Magn. Magn. Mater. 310 (2007) 2006-2008. doi:10.1016/j.jmmm.2006.10.771.

14. R.K. Kotnala, S. Kumar, J. Shah, Alimuddin, M. Hashim, R. Kumar, S.E. Shirsath, Influence of $\mathrm{Cr} 3+$ ion on the structural, ac conductivity and magnetic properties of nanocrystalline $\mathrm{Ni}-\mathrm{Mg}$ ferrite, Ceram. Int. 39 (2013) 1807-1819. doi:10.1016/j.ceramint.2012.08.028.

15. M. Lakshmi, K.V. Kumar, K. Thyagarajan, Structural and Magnetic Properties of Cr-Co Nanoferrite Particles, Adv. Nanoparticles. 05 (2016) 103-113. doi:10.4236/anp.2016.51012.

16. P. Priyadharsini, A. Pradeep, P.S. Rao, G. Chandrasekaran, Structural, spectroscopic and magnetic study of nanocrystalline Ni-Zn ferrites, Mater. Chem. Phys. 116 (2009) 207-213. doi:10.1016/j.matchemphys.2009.03.011.

17. S.A. Saafan, T.M. Meaz, E.H. El-Ghazzawy, Study of DC conductivity and relative magnetic permeability of nanoparticle $\mathrm{NiZnFe2O4/PPy} \mathrm{composites,}$ J. Magn. Magn. Mater. 323 (2011). doi:10.1016/j.jmmm.2011.01.010.

18. M.A. Amer, T.M. Meaz, A.G. Mostafa, H.F. El-Ghazally, Structural and physical properties of the nano-crystalline Al-substituted $\mathrm{Cr}-\mathrm{Cu}$ ferrite, $\mathrm{J}$. Magn. Magn. Mater. 343 (2013) 286-292. doi:10.1016/j.jmmm.2013.05.008.

19. M.A. Amer, T.M. Meaz, A.G. Mostafa, H.F. El-ghazally, Influence of 
annealing process on phase transition of $\mathrm{Cu}-\mathrm{Al}$ nanoferrites synthesized by a coprecipitation method, Mater. Sci. Semicond. Process. 36 (2015) 49-56. doi:10.1016/j.mssp.2015.03.027.

20. E.H. El-Ghazzawy, M.A. Amer, Structural, elastic and magnetic studies of the as-synthesized Co1-xSrxFe2O4 nanoparticles, J. Alloys Compd. 690 (2017). doi:10.1016/j.jallcom.2016.08.135.

21. H. Ibach, H. Luth, Solid-state physics: An introduction to principles of materials science, Forth edit, Springer, Germany, 2010. doi:10.1007/978-3540-93804-0.

22. R.E.H. Hummel, Understanding Materials Science, second edd, Springer, USA, 2004.

23. K.B. Modi, S.J. Shah, N.B. Pujara, T.K. Pathak, N.H. Vasoya, I.G. Jhala, Infrared spectral evolution, elastic, optical and thermodynamic properties study on mechanically milled Ni0.5Zn $0.5 \mathrm{Fe} 2 \mathrm{O} 4$ spinel ferrite, J. Mol. Struct. 1049 (2013) 250-262. doi:10.1016/j.molstruc.2013.06.051.

24. E.H. El-Ghazzawy, Effect of heat treatment on structural, magnetic, elastic and optical properties of the co-precipitated $\mathrm{Co} 0.4 \mathrm{Sr} 0.6 \mathrm{Fe} 2 \mathrm{O} 4$, J. Magn. Magn. Mater. 497 (2020) 166017. doi:10.1016/j.jmmm.2019.166017.

25. S.M. Patange, S.E. Shirsath, K.S. Lohar, S.G. Algude, S.R. Kamble, N. Kulkarni, D.R. Mane, K.M. Jadhav, Infrared spectral and elastic moduli study of NiFe2-xCrxO4 nanocrystalline ferrites, J. Magn. Magn. Mater. 325 (2013) 107-111. doi:10.1016/j.jmmm.2012.08.022.

26. A. Goldman, Modern Ferrite Technology, 2nd Ed, Springer US, United States of America, 2006. doi:10.1007/978-0-387-29413-1.

27. F.S. Tehrani, V. Daadmehr, A.T. Rezakhani, R.H. Akbarnejad, S. Gholipour, Structural, magnetic, and optical properties of zinc-and copper-substituted nickel ferrite nanocrystals, J. Supercond. Nov. Magn. 25 (2012) 2443-2455. doi:10.1007/s10948-012-1655-5.

28. S. Singhal, S. Bhukal, J. Singh, K. Chandra, S. Bansal, Optical, X-ray diffraction, and magnetic properties of the cobalt-substituted nickel chromium ferrites (CrCoxNil-xFeO4, $\mathrm{x}=0,0.2,0.4,0.6,0.8,1.0$ ) synthesized using sol-gel autocombustion method, J. Nanotechnol. 2011 (2011). doi:10.1155/2011/930243.

29. Y.B. Kannan, R. Saravanan, N. Srinivasan, I. Ismail, Sintering effect on structural, magnetic and optical properties of Ni0.5Zn0.5Fe2O4ferrite nano particles, J. Magn. Magn. Mater. 423 (2017) 217-225. doi:10.1016/j.jmmm.2016.09.038.

30. Y.M. Galperin, Introduction to Modern Solid State Physics, second edd, CreateSpace Independent Publishing Platform, Oslo, (2014).

31. R. Köferstein, T. Walther, D. Hesse, S.G. Ebbinghaus, Preparation and characterization of nanosized magnesium ferrite powders by a starch-gel process and corresponding ceramics, J. Mater. Sci. 48 (2013) 6509-6518. doi:10.1007/s10853-013-7447-x.

32. P. Thandapani, M. Ramalinga Viswanathan, J.C. Denardin, Magnetocaloric 
effect and universal curve behavior in superparamagnetic zinc ferrite nanoparticles synthesized via microwave assisted co-precipitation method, Phys. Status Solidi Appl. Mater. Sci. 215 (2018) 1-9. doi:10.1002/pssa.201700842.

33. S.A. Saafan, T.M. Meaz, E.H. El-Ghazzawy, M.K. El Nimr, M.M. Ayad, M. Bakr, A.C. and D.C. conductivity of NiZn ferrite nanoparticles in wet and dry conditions, J. Magn. Magn. Mater. 322 (2010) 2369-2374. doi:10.1016/j.jmmm.2010.02.039.

34. V. Kumar, A. Rana, M.S. Yadav, R.P. Pant, Size-induced effect on nanocrystalline CoFe 2 O 4, J. Magn. Magn. Mater. 320. 320 (2008) 1729-1734. doi:10.1016/j.jmmm.2008.01.021.

35. G.C. Papaefthymiou, S.R. Ahmed, P. Kofinas, Magnetic and Structural Characerization of $\mathrm{CoFe} 2 \mathrm{O} 4$ Nanoparticles Encapsulated Within Block Copolymer Films, 06 Rev.Adv.Mater.Sci. 10 (2005) 306-313.

36. R. Topkaya, U. Kurtan, A. Baykal, H. Sozeri, M.S. Toprak, Polymer Assisted Co-precipitation Synthesis and Characterization of Polyethylene Glycol (PEG)/CoFe2O4 Nanocomposite, J. Inorg. Organomet. Polym. Mater. 23 (2013) 592-598. doi:10.1007/s10904-012-9818-1.

37. C. Chang, J.P. Shyu, Effects of porosity on coercive force of particulate medium, Chinese J. Phys. 28 (1990) 29-36.

38. E.H. El-Ghazzawy, Conductivity and dielectric relaxation properties of annealed Cr-substituted Ni-ferrite nanoparticles, J. Electron. Mater. 46 (2017) 5599-5607. doi:10.1007/s11664-017-5633-3.

39. H. Deligöz, A. Baykal, M.S. Toprak, E.E. Tanriverdi, Z. Durmus, H. Sözeri, Synthesis, structural, magnetic and electrical properties of Co1-xZnxFe2O4(x $=0.0,0.2)$ nanoparticles, Mater. Res. Bull. 48 (2013) 646-654. doi:10.1016/j.materresbull.2012.11.032.

40. A. Ashok, T. Somaiah, D. Ravinder, C. Venkateshwarlu, Electrical properties of cadmium substitution in nickel ferrites, World J. Condens. Matter Phys. 2 (2012) 257-266.

41. J.P. Suchet, Electrical conduction in solid materials, first edit, PERGAMON PRESS LTD., Luxembourg, 1975. 
